\title{
Development of a Carbon Emission Calculations System for Optimizing Building Plan Based on the LCA Framework
}

\author{
Feifei Fu, ${ }^{1}$ Hanbin Luo, ${ }^{1}$ Hua Zhong, ${ }^{2}$ and Andrew Hill ${ }^{3}$ \\ ${ }^{1}$ School of Civil Engineering \& Mechanics, Huazhong University of Science \& Technology, Wuhan 430074, China \\ ${ }^{2}$ School of Architecture, Design and the Built Environment, Nottingham Trent University, Nottingham NG1 4BU, UK \\ ${ }^{3}$ William Hill Building Contractors Ltd., Nottingham NG3 7EJ, UK
}

Correspondence should be addressed to Hanbin Luo; lhblhb1963@vip.sina.com

Received 28 February 2014; Revised 4 May 2014; Accepted 7 May 2014; Published 11 June 2014

Academic Editor: Changzhi Wu

Copyright (C) 2014 Feifei Fu et al. This is an open access article distributed under the Creative Commons Attribution License, which permits unrestricted use, distribution, and reproduction in any medium, provided the original work is properly cited.

\begin{abstract}
Life cycle thinking has become widely applied in the assessment for building environmental performance. Various tool are developed to support the application of life cycle assessment (LCA) method. This paper focuses on the carbon emission during the building construction stage. A partial LCA framework is established to assess the carbon emission in this phase. Furthermore, five typical LCA tools programs have been compared and analyzed for demonstrating the current application of LCA tools and their limitations in the building construction stage. Based on the analysis of existing tools and sustainability demands in building, a new computer calculation system has been developed to calculate the carbon emission for optimizing the sustainability during the construction stage. The system structure and detail functions are described in this paper. Finally, a case study is analyzed to demonstrate the designed LCA framework and system functions. This case is based on a typical building in UK with different plans of masonry wall and timber frame to make a comparison. The final results disclose that a timber frame wall has less embodied carbon emission than a similar masonry structure. $16 \%$ reduction was found in this study.
\end{abstract}

\section{Introduction}

$\mathrm{CO}_{2}$ as a dominate greenhouse gas is the most serious threat to global warming. How to reduce $\mathrm{CO}_{2}$ is definitely a hot topic in all industries with the increasing focus on climate change [1]. According to Intergovernmental Panel on Climate Change (IPCC) [2], buildings consumed 40\% energy sources and led to $36 \%$ energy related carbon emission in industrialized countries. Therefore, the building industry has become a crucial global target to reduce $\mathrm{CO}_{2}$ emission. All developed countries have recognized the building industry as the key control point of the low carbon economy and a sustainable environment. China has also promised that carbon emission will reduce $40 \%-45 \%$ per GDP unit from 2009 to 2020 [3].

Reducing carbon emission has been a significant focus, so LCA as an internationally standardized method is widely applied in current industries [4]. It quantifies all relevant emissions and resources consumed and the related environmental and health impacts and resource depletion issues that are associated with products [5]. The International Organization for Standardization (ISO) 14040 and 14044 standards provides an indispensable framework for LCA [6]. According to the application in buildings based on LCA, many studies have identified the overall impact of the construction of buildings on the environment, and the analysis objectives and results are quite different. Table 1 shows a summary of recent literature on this area.

Most of the current papers mainly studied the analysis of building life cycle and very few have focused on the construction phase in particular. However, it has been suggested that between $2 \%$ to $36 \%$ of a traditional house's lifetime carbon emission is contributed by the primary materials, manufacture, transportation, and construction [7]. The ratio is even higher in some office buildings [8]. Therefore, this paper aims to establish a calculation method for carbon emissions focus on building construction only.

Many tools were developed to support LCA method to make the LCA analysis more convenient and automatic. The European Commission and Institute for Environment and 
TABLE 1: An literature overview of carbon case studies.

\begin{tabular}{lll}
\hline References & Assessment phases & Objects of comparison \\
\hline$[20]$ & Construction/use/disposal & $\begin{array}{l}\text { (i) Recycling disposal } \\
\text { (ii) } 100 \% \text { landfill disposal }\end{array}$ \\
\hline$[11]$ & Construction/maintenance/disposal/operation & $\begin{array}{l}\text { (i) Wooden type of housing } \\
\text { (ii) Steel reinforced concrete type of housing }\end{array}$ \\
\hline$[21]$ & Construction/use/disposal & $\begin{array}{l}\text { (i) An existing building } \\
\text { (ii) A high-strength concrete building }\end{array}$ \\
\hline$[22]$ & Construction/operation/maintenance/disposal & $\begin{array}{l}\text { (i) Existing apartment house } \\
\text { (ii) Standard apartment house }\end{array}$ \\
\hline$[23]$ & Material production/construction/demolition & (i) The bamboo-structure \\
\hline$[24]$ & Construction/operation/maintenance/renovation & (ii) Brick-concrete building
\end{tabular}

Sustainability [9] conducted a survey with these LCA tools in 2008. 42 tools and 26 databases already available in the market have been classified. However, the report demonstrated that there are limited specific tools for buildings, specifically in building construction. Therefore, the aim of this paper is to design a LCA tool to calculate and compare the embodied carbon and energy used during the construction stage for different plans and then to identify the crucial contributors that could deliver reductions in embodied carbon.

\section{Literature Review}

The growing importance of environmental issues, such as climate change, has created a need to evaluate the impacts of the products used in construction. One of the principle techniques to enable the quantification and comparison of the environmental impact of a product is LCA. This is defined as an objective methodology to analyze and quantify the environmental consequences of products and services during their whole life cycle [10].

Researchers have intensively investigated the energy and carbon implications of building materials and design in "cradle to grave" life cycle studies of a house or its key components. Most of the previous research papers mainly studied the analysis of buildings' life cycle and very few focused on the construction phase in particular and provide the detailed information in this phase, such as building materials which include brick, concrete, lime, gravel, and sand, transport distance of each material to site, equipment inputs of truck, dozer, digger, and street roller, and energy includes diesel and electricity to drive engineering equipment.

However, some studies have realized the importance of environment impact from the construction phase. Gerilla et al. showed that much of the environmental impacts from construction are on the global warming potential due to high carbon emissions [11]. Monahan and Powell compared the embodied carbon in a low energy affordable house constructed using a novel offsite panelized modular timber frame system [12], and Yan et al. present a case study of greenhouse gas (GHG) emissions in building construction in Hong Kong [13].
LCA studies are case sensitive because they include specific technologies and processes for material extraction, manufacturing, and transportation and installation, which often differ with time and place. Most carbon emission studies use carbon dioxide equivalent $\left(\mathrm{CO}_{2} \mathrm{e}\right)$ to measure GHG emissions, and the embodied environmental impact (carbon related) of building construction can be cut in half when alternative building materials and technologies are employed. For example, wooden structures are generally found to be preferable since they are less carbon intensive compared to nonwooden structures [14].

Meanwhile, many tools programs were developed to support the LCA method to make the LCA analysis more convenient and straight forward, like SimaPro which has already been widely used in studies for assisting the assessment of environmental performance [8]. The European Commission summarized 42 LCA tools programs in the report [9]. According to a survey on 60 LCA practitioners carried out in 2006, GaBi and SimaPro were the most popular LCA tools that occupied $58 \%$ and $31 \%$ of the market [15]. Focusing on the building industry, the BEES (America) [16], Athena (Canada) [17], CASBEE (Japan) [18], and WRATE (UK) [19] are the typical tools used. BEES and Athena include all the stages in the building's life cycle. CASBEE has a variety of versions for new building work, exciting building, and renovation. WRATE mainly focuses on comparing the environmental impacts of different municipal waste management systems. However, there is no specific tool that focuses on the accounting of carbon emissions for building construction processes.

\section{LCA Method for Building Construction}

LCA is a methodological tool that applies life cycle thinking in a quantitative way on environmental analysis of activities related to processes or products. LCA has widespread application in most industries for environmental performance assessment. This study applies this LCA method for building construction to calculate the carbon emission. A partial LCA framework is established based on the characteristics of construction, including the scope, the system boundary, analysis inventory, impact assessment, and result interpretation. 
3.1. LCA Framework. ISO 14040 defines LCA as the "compilation and evaluation of the inputs, outputs and the potential environmental impacts of a product system throughout its life cycle." The general framework for LCA has been standardized by ISO. It consists of the following elements [6].

(1) Goal, Scope, and Definition. Goal and scope definition depends upon the subject and the intended use of the study and can vary considerably depending upon the particular project [6], including defining the functional unit, the system boundary, and the carbon or energy flow. Regarding the LCA application in building construction, this study mainly focuses on the materials from cradle to site, equipment activities, and waste disposal. The goal of this study is to calculate and compare the embodied carbon and energy used during construction for different plans and to identify the crucial contributors that could deliver reductions in embodied carbon.

(2) Life Cycle Inventory (LCI). This phase is a data collecting activity to input-output analysis for all the processes and elements within the system boundary. A specific inventory is provided in the case study.

(3) Life Cycle Impact Assessment (LCIA). LCIA evaluates the significance of potential environmental impacts using the LCI results and provides information for the final interpretation phase.

(4) Interpretation. Interpretation is the phase where the results of the LCI and LCIA are interpreted according to the goal of the study and where sensitivity and uncertainty of analysis are performed to qualify the results and the conclusions.

This paper concerns the input-output of the carbon source in the building construction phase and intends to design a flexible information system used to calculate the building's overall carbon footprint in construction and identify ways of reducing it and assess and compare the carbon performance of different design and management choices. It means, based on the LCA framework applied in building construction, defining the scope and boundaries, the inventory analysis, impact assessment, and interpretation which will be applied to the designed system.

3.2. System Boundaries. The study demonstrated using 20 papers related to the calculation of GHG or $\mathrm{CO}_{2}$ emissions of buildings that GHG emissions in building construction work and are mainly from six sources: (1) manufacture of building materials; (2) transportation for building materials; (3) transportation for construction equipment; (4) energy consumption of construction equipment; (5) transportation for workers; and (6) disposal of construction waste [13]. Sharma et al. also concluded that the key factors for energy use in buildings are transportation, building material production, and construction, during the preuse life cycle phase based on the analysis of over 40 studies [25].

The analysis boundaries are dependent upon the subject and the objects of the study. When defining the analysis boundary of the LCA application in building construction, the key point is to catch the most capital items rather than all the processes and elements involved in the construction. It is better to simplify the inventory and highlight these. Therefore, in this paper, the system boundaries are from the cradle to handover of the completed building for which four sources of carbon emissions have been identified: manufacture and transportation of building materials; energy consumption of construction equipment; and disposal of construction waste. The system boundaries and carbon emission flow in this study are shown in Figure 1.

(i) Embodied Carbon of Materials and Products Used in Construction. Embodied carbon of materials used in construction is decided by the types and amount of the materials used in construction.

(ii) Transport of the Materials and Products to Site. The transportation of construction materials means the energy construction and carbon release during the materials transportation from cradle to the construction site by different transport types. Usually, the transport types include road, railway, and ocean shipping.

(iii) Energy Consumption of Construction Equipment. The carbon emission of equipment mainly comes from the fuel and electricity consumption for the equipment during the construction activities, such as hoist and assemble.

(iv) Disposal of Construction Waste. The carbon emission in disposal mainly comes from the saved embodied carbon emission of recycle materials and the transportation of materials from the construction site to other areas after construction process.

The infrastructure required in construction, such as roads, warehouses, and the operational activities associated with administration and the workforce themselves (including their transport to site), is considered to be outside of the bounds as they do not contribute directly to the construction process of the building considered.

\section{Comparison of Current LCA Tools}

In recent years life cycle thinking has become a key focus in environmental policy making. Many tools were developed to support LCA method to make the LCA analysis more convenient and automatic. These tools dramatically improved the analysis efficiency and expanded the application of LCA. Although these analysis tools shared the same theory, the functions' performance, the system framework and, even application are totally different, and the variety of these tools brings the problem of decision-making difficulties for the users.

According to a survey on 60 LCA practitioners carried out in 2006, GaBi and SimaPro were the most popular LCA tools, accounting for $58 \%$ and $31 \%$ of the market, respectively, and $11 \%$ for other tools, like TEAM, BEES, and so forth [15]. 


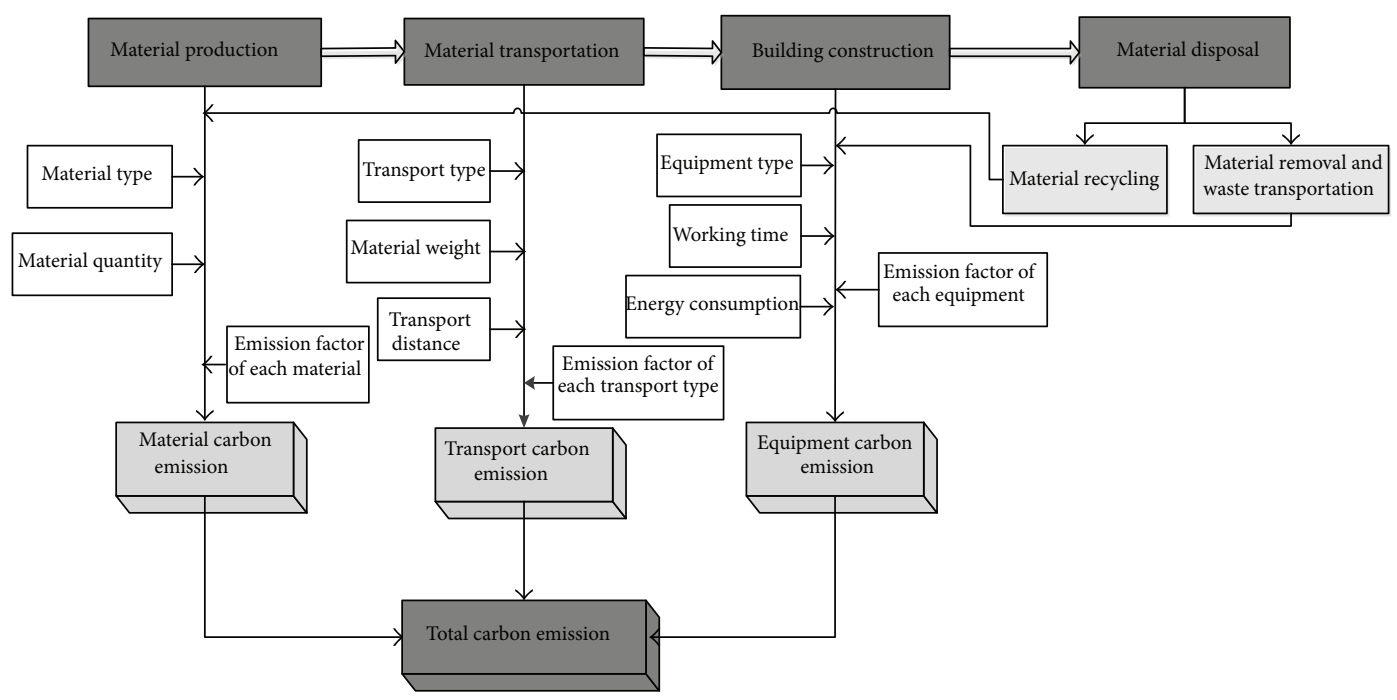

FIGURE 1: System boundaries of the construction process.

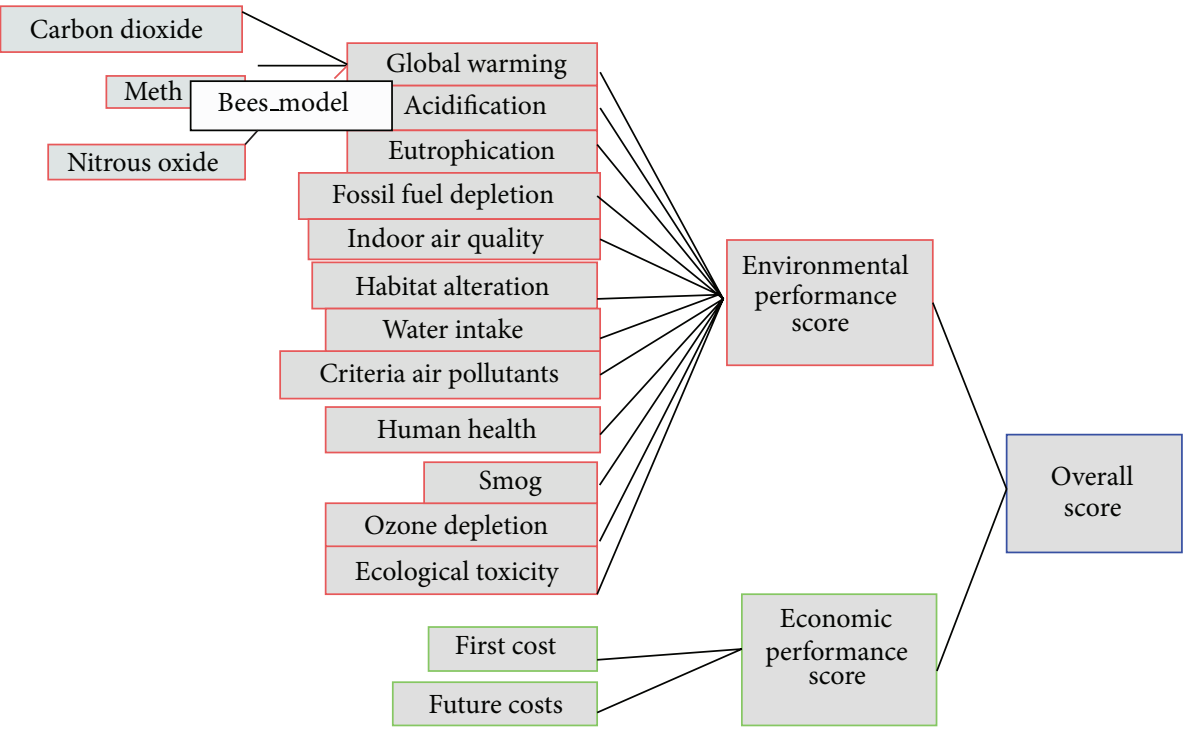

Figure 2: BEES model.

Considering the popularity, five worldwide leading LCA tools were involved in this study to make a comparison.

\subsection{LCA Tools for Carbon Emission Calculation}

(1) BEES 4.0. BEES (building for environmental and economic sustainability) is a free LCA tool developed by the NIST (National Institute of Standards and Technology). It mainly is applied in the building industry for the selection of environmentally preferable building products, and also including cost-effective analysis. The tool was designed to Windows-based decision support, aimed at designers, builders, and product manufacturers [16]. All stages in the life of a product are analyzed. There are 12 figures for environmental performance and two figures for economic performance. The BEES model [16] is shown in Figure 2.
(2) Athena Impact Estimator 4.2. The Athena Institute's Environmental Impact Estimator is a LCA tool for assessment of the whole building or assembly level. This tool lets architects, engineers, and researchers assess the environmental implications of industrial, institutional, office, multiunit residential, and single-family residential building design. This tool is able to make comparisons between alternative designs [17]. The Estimator takes into account the environmental impacts at all stages as well [17].

(3) TEAM 5.1. TEAM integrates impact calculation functionalities and sensitivity analysis in one single executable and an integrated database manager. It means TEAM allows the user to build and use a large database, to model any system representing the operations associated with products, processes, and activities and to calculate the associated life cycle inventories and potential environmental impacts in compliance 


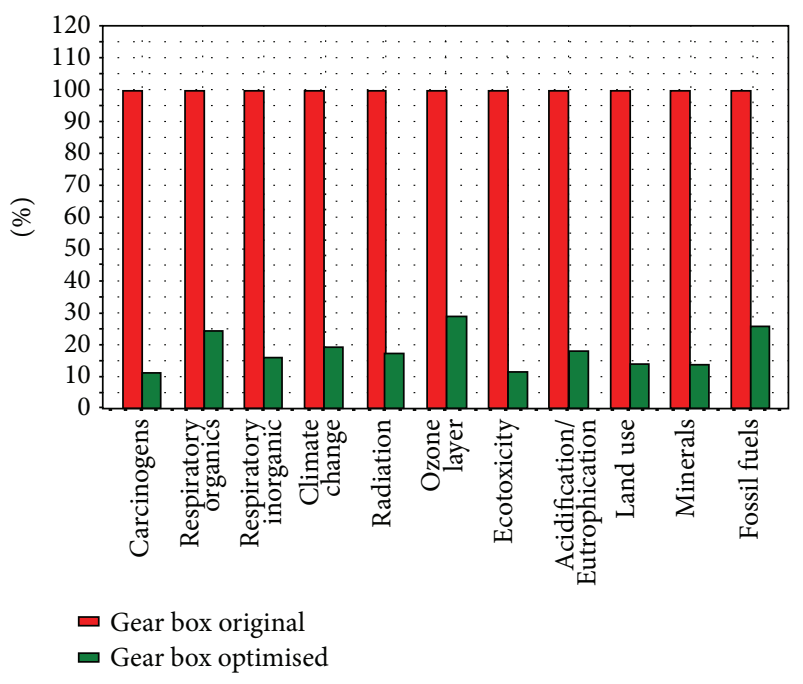

FIGURE 3: Sustainability comparison in SimaPro.

with the ISO 14040 series of standards. Additionally, TEAM allows running simulations and scenario comparison by defining variables [26].

(4) SimaPro 7.2. SimaPro LCA tool is used throughout the world. SimaPro 7.2 is a world leading sustainable tool developed by PRe Consultants. It provides a professional tool to collect, analyze, and monitor the environmental performance of products and services. Comparison result by SimaPro is shown in Figure 3.

SimaPro is famous for its flexibility in handling different impact assessment methods. SimaPro comes with a huge database included, and it is even possible to make links to outside data sources. The database can be modified, extended, and based on the customer's own requirement.

(5) $\mathrm{GaBi} 4$. GaBi 4 is a world-wide leading tool for modeling products and systems from a life cycle perspective. The user should build a lifecycle of the product as Figure 4 shows. GaBi 4.2 allows creating models based on physical process chains (engineering approach). For a detailed analysis, $\mathrm{GaBi}$ analyst offers scenario analysis, parameter variation, sensitivity analysis, and a fully user controlled Monte Carlo analysis. Figure 4 shows LCA results in GaBi.

Databases delivered by production engineer can be remotely serviced, allowing for the updating of data directly into the customer's models and enable the customer to manage his/her databases in an efficient way and assure consistent databases.

4.2. Comparison Analysis. The difference among these five LCA tools is not only the performance result, but also the application range. According to the introduction of each tool demonstrated above, the comparison analysis is shown in Table 2.

Apart from these five typical tools, others, like CASBEE (comprehensive assessment system for built environment efficiency) from Japan [18], WRATE (waste and resources assessment tool for the environment) from UK [19], and so forth, are also widely used in the building industry. Among these tools, GaBi and SimaPro as they have flexible operation and a powerful database are the most widespread application LCA tools. Although these tools can definitely analyze the environmental efficiency of projects, $\mathrm{GaBi}$ and SimaPro are mostly used in manufacturing rather than the building industry. Some pertinent functions and data accuracy may not be suitable enough for the building industry and may not be suitable for buildings. According to the survey report of the European Commission [9], most of the current tools are designed for all industries, and only a half of them are addressed to a specific sector amongst 42 LCA tools investigated. The most represented are building/construction processes, waste/end of life scenarios, and crops/agricultural products.

Focusing specifically on the building industry, the BEES (America), Athena (Canada), CASBEE (Japan), and WRATE (UK) are the most typical tools. BEES and Athena include all the stages in the building's life cycle. CASBEE has a variety of versions for new building, existing building, and renovation; WRATE mainly focuses on comparing the environmental impacts of different municipal waste management systems.

For most of the contractor or designer of building project, the sustainable performance in the construction phase attracts more concern with the resultant carbon emission. However, there are limited specific tools for buildings, specifically in building construction. Although some of them include the construction phase, the completely sources of carbon emission in construction are not integrated in one tool; some only focused on manufacture of building materials, some only focused on transportation for building materials or construction equipment, and some only focused on disposal of construction waste. Thus an integrated tool for all the activities about carbon emission in construction phase is needed. In addition, the less the better; obviously, currently tools are somehow too complicated and theoretical for the end users. Therefore, this study aims to develop a simple but practical LCA system focusing on construction stage. It could be easy to handle and useful for participants to calculate and compare the carbon emission for different construction plans and then to identify the crucial contributors that could deliver reductions in embodied carbon.

Apart from quantitative calculation and comparing the carbon emission for different construction plans, the designed system also aims to raise awareness of the benefits of sustainable design for building construction and aid users in assessing the embodied energy and carbon savings that can occur by designing for construction. This could definitely provide assistance in the decision making process and promote continuing dialogue between the interested parties involved.

\section{Carbon Emission Calculation System Schematic Design}

5.1. System Structure. Based on the partial LCA framework conducted in the construction phase, the information system 


\begin{tabular}{|c|c|}
\hline \multicolumn{2}{|l|}{ Inputs/Outputs } \\
\hline & Gear Rack \\
\hline EI99, HA (Hierarchist approach) & 0.51842 \\
\hline$E 199, \mathrm{HA}$, Ecosystem quality, Acidification/nutrification & 0.0033319 \\
\hline EI99, HA, Ecosystem quality, Ecotoxicity & 0.0003497 \\
\hline EI99, HA, Ecosystem quality, Land conversion & \\
\hline EI99, HA, Ecosystem quality, Land-use & 2. $1989 \mathrm{E}-006$ \\
\hline EI99, HA, Human health, Carcinogenic effects & 0.43078 \\
\hline EI99, HA, Human health, Climate Change & 0.020363 \\
\hline E199, HA, Human health, Ozone layer depletion & $2,6512 E-007$ \\
\hline EI99, HA, Human health, Radiation & $2.3393 E-006$ \\
\hline EI99, HA, Human health, Respiratory (inorganic) & 0.033783 \\
\hline E199, HA, Human health, Respiratory (organic) & $3.4688 \mathrm{E}-005$ \\
\hline EI99, HA, Resources, Fossil fuels & 0.028921 \\
\hline EI99, HA, Resources, Minerals & 0.00084869 \\
\hline
\end{tabular}

(a)

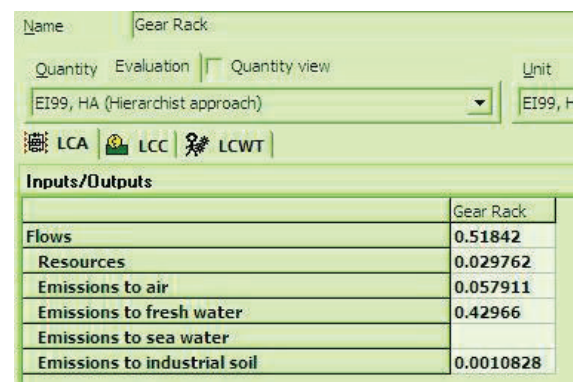

(b)

FIgURE 4: GaBi 4 LCA results.

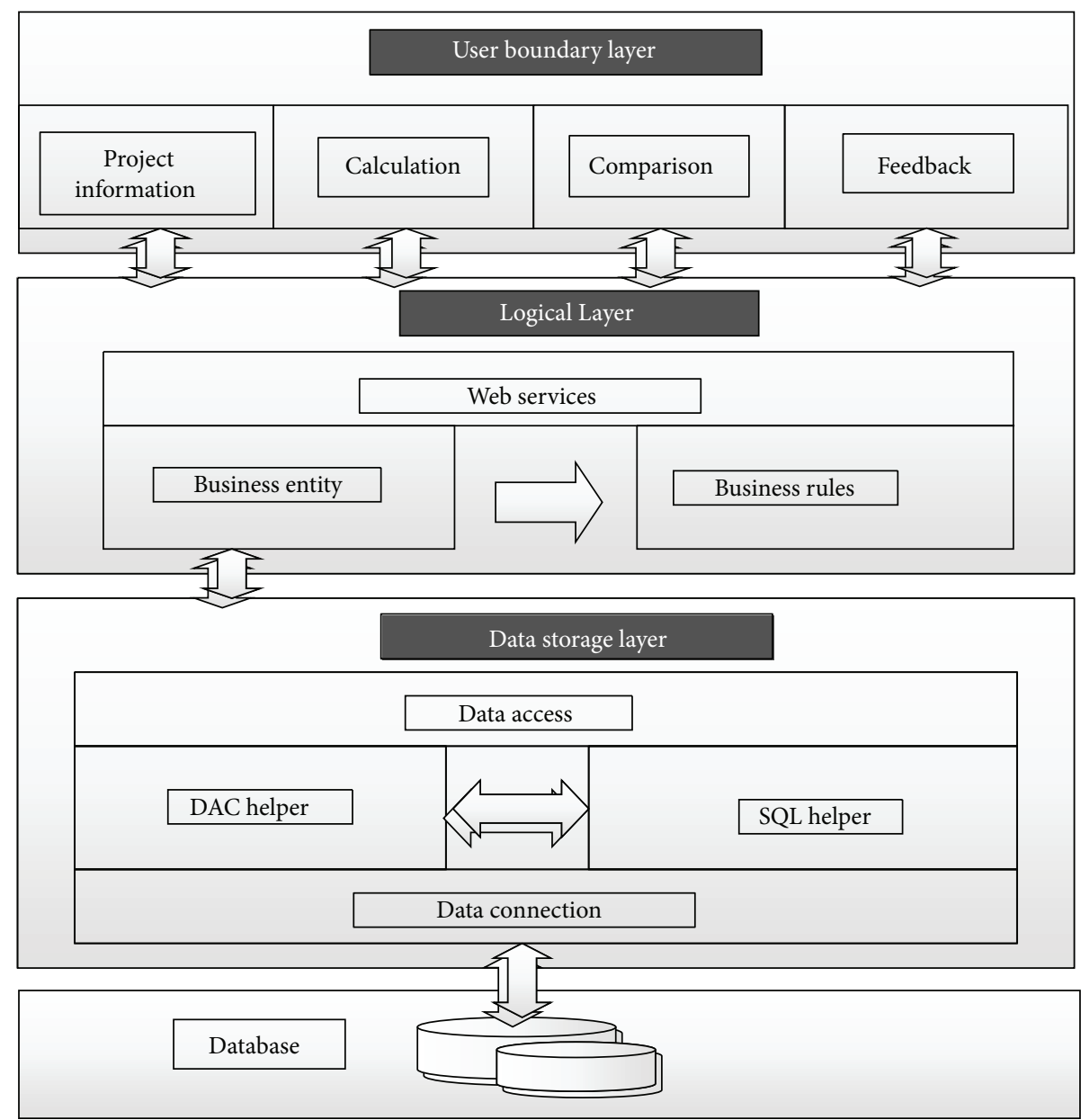

FIGURE 5: The system structure.

was developed to calculate the carbon emission of the construction plan by the designers for sustainable optimization and can also be used to check and compare the carbon emission of different construction plans by the owners.

In consideration of safety and privacy for the project information, browser/server (B/S) mode was adopted to develop this carbon emission calculation system. The system has a three-tier (boundary layer, logical layer, and data storage layer) distributed and collaborative structure. Boundary layer corresponds to the client. Logical layer corresponds to the
World Wide Web server in which the main program of the system is deployed, and data of the main programs is exchanged through web service. Data storage layer corresponds to the database server. Figure 5 shows the system structure.

In addition, the structure of this system involves three major processes: (1) calculation: calculate and assess the carbon emission of the building construction processes based on LCA framework; (2) comparison: provide a comparison action to analyse the carbon emission of embodied material, 
TABLE 2: Comparison results.

\begin{tabular}{|c|c|c|c|c|c|}
\hline Tools & Country & Developer & Main functions & $\begin{array}{c}\text { Database } \\
\text { extensibility }\end{array}$ & Application range \\
\hline BEES 4.0 & America & $\begin{array}{l}\text { National Institute of } \\
\text { Standards and Technology }\end{array}$ & $\begin{array}{l}\text { (i) Life cycle costing assessment } \\
\text { (ii) Life cycle impact assessment }\end{array}$ & Fixed & Building \\
\hline $\begin{array}{l}\text { Athena Impact } \\
\text { Estimator } 4.2\end{array}$ & Canada & $\begin{array}{l}\text { Athena Sustainable } \\
\text { Materials Institute }\end{array}$ & Life cycle impact assessment & Fixed & Building \\
\hline TEAM 4.6 & France & $\begin{array}{l}\text { Ecobilan-Price water } \\
\text { house Coopers }\end{array}$ & $\begin{array}{l}\text { (i) Life cycle costing assessment } \\
\text { (ii) Life cycle impact assessment } \\
\text { (iii) Sensitivity and uncertainty } \\
\text { analysis }\end{array}$ & Flexible & All industries \\
\hline SimaPro7 & Netherlands & PRé Consultants B.V. & $\begin{array}{l}\text { (i) Life cycle impact assessment } \\
\text { (ii) Database Management }\end{array}$ & Flexible & All industries \\
\hline $\mathrm{GaBi} 4$ & Germany & PE International GmbH & $\begin{array}{l}\text { (i) Life cycle impact assessment } \\
\text { (ii) Database management }\end{array}$ & Flexible & All industries \\
\hline
\end{tabular}

transportation types, or equipment between original construction plan and alternative plans; (3) feedback: make the decision and feedback the report after comparing the carbon emission of the different scenarios.

The existing database including the carbon emission factors of materials and transport used within this system is based on an inventory of carbon and energy data (ICE) [27], and the database of carbon emission factors of construction equipment is from IPCC [2]. However, it provides an open access for users to edit or revise the data for special performance or add new factors into the database for using new technology or materials introduced to the market.

5.2. Function Description. This carbon calculation system measures the greenhouse gas impacts of construction activities in terms of carbon dioxide equivalency $\left(\mathrm{CO}_{2} \mathrm{e}\right)$. It does this by calculating the embodied $\mathrm{CO}_{2} \mathrm{e}$ of materials plus the $\mathrm{CO}_{2} \mathrm{e}$ associated with their transportation. It also considers equipment used and waste disposal management.

This system can be used to assess and compare the sustainability performance of different design and management choices at the design stage. It helps to highlight where you can make better carbon savings on specific construction projects. It can also be used to help calculate the users' overall carbon emission from construction and identify areas realizing better savings. It additionally contributes to the overall emissions and quantification in the savings with carbon dioxide emissions.

According to the framework of carbon sources based on LCA framework described in Figure 1, the construction information about carbon emission models should be inputted at the first step. After the related construction information and types are defined, the key procedure is the relationships linking between the inputted construction information shown in Figure 1 and related carbon coefficient by the built-in database; it then automatically calculates the embodied and transports carbon emission for each project. In addition, for the demand of most users, the different plans can be compared within the system, and feedback is provided as to which is the best option.
The system operating process can be shown in Figure 6.

This system was designed to allow the builders to analyze materials specified in construction projects that it was involved with and to prepare alternative material options based on the experience and knowledge where such alternatives could improve upon preexisting project carbon emission levels, whilst also relating to its impact on project cost. Furthermore, it makes an improved connection between the construction contractor, designer, and owner in the critical and ethical area of construction sustainability. It will pass on invaluable contractor expertise in the field of carbon emission directly to the client, therefore making the client aware of options and alternatives that they may not have previously known within the procurement process. This will also ultimately allow the client to play an active and influential role in supporting a sustainable approach.

\section{Case Study}

6.1. Background of the Case. The case study aimed at demonstrating how to use the designed information system based on the LCA framework to analyse the carbon emission of different construction plans, which can enlighten the designer enabling the awareness of options and alternatives that may not have been previously considered in the procurement process.

Two construction plans are analyzed to make the comparison. The data was derived from the construction plan, drawings, and bills provided by the builders. The transport distances were estimated by the builders according to the interview with them.

6.1.1. Project Plans and Boundary. The case presented here is a single story training center of approximately $180 \mathrm{~m}^{2}$ constructed in 2010 in the midlands, UK. Accommodation comprises teaching room, offices, stores, WC accommodation, and a meeting room. Figure 7 shows the completed building. 


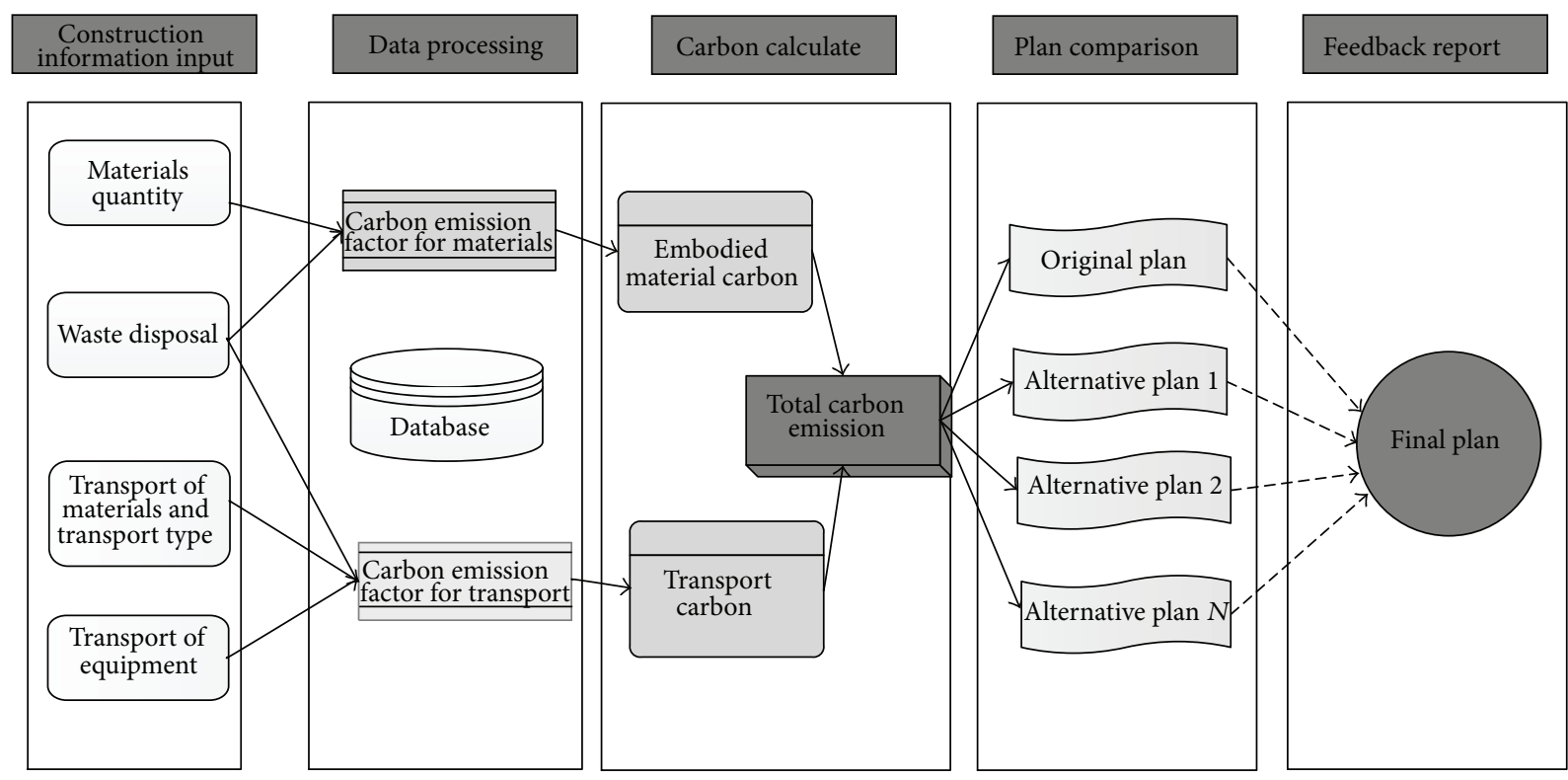

FIGURE 6: System operating process flow chart.

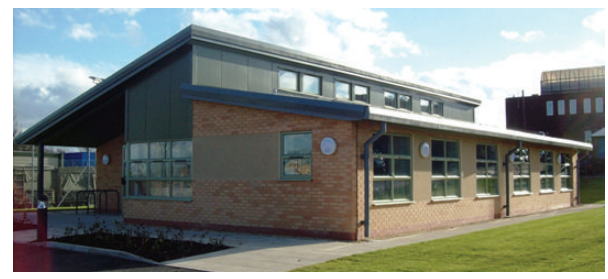

FIGURE 7: Picture of the case building.

There are two construction plans provided here to make the comparison.

Plan 1 (Masonry Wall). The building was constructed using traditional approaches. A combined masonry frame system with additional insulation materials is used. The substructure consists of precast steel reinforced beams with an infill of concrete. Walls are formed from the masonry work consisting of brick and blocks with metal composite panel metal wall and roof cladding.

Plan 2 (Timber Frame Wall). Although this project has already been completed, for the sake of better describing the designed information system and in order to demonstrate the carbon influence of alternative material plan, this study assumes that the traditional masonry wall is replaced by the timber frame in plan 2. No other parameters were altered. The use of timber as a facade material is becoming more prevalent in commercial buildings as an aesthetic acceptance towards a building's sustainable credentials, but is still uncommon in mass produced housing in the UK [12].

As data is hard to obtain about the equipment and waste in construction, the case study here only focuses on the embodied carbon emission of the materials and their transportation from cradle to site. In addition, the infrastructure or groundwork, water pipes, heaters, or other equipment, and the furniture are all excluded.

6.1.2. Inventory and Source. In order to systematically detect and quantify the building shell components, 5 subsystems were identified as substructure, roof, walls, windows and doors, and ceiling. The inventory of specific material and transportation happened in plan 1 as shown in Table 3.

The project information and material quantities were obtained from the construction plan, drawings, and bills provided by the builders. The transport distances were estimated by the builders according to the interview with them.

\subsection{The Carbon Emission Calculation System Operate Process}

6.2.1. Information Input. The carbon footprint calculation system is created to quantity the embodied carbon emission of the construction project and to help the designers and builders assess the construction plan in a sustainable way. It can also be used in the design stage to make a supported decision in obtaining the most rational material and construction process plan.

(1) Input the Project and Plan Information. The project must be created at the beginning when using this system, including the basic information about this project, such as the project title, designer, constructor, and building type. Then, plan 1 "masonry wall" and plan 2 "timber frame" can be created below this project.

(2) Input the Specific Material Information. The core information that must be inputted into this system is the material and transport inventory. This means in effect how to input Table 3 for automatic calculation and analysis. The database of the system already contains most of the building materials; more 
TABLE 3: Inventory of materials and transport in plan 1.

\begin{tabular}{|c|c|c|c|c|c|}
\hline Building subsystem & Material & Quantity (t) & $\begin{array}{c}\text { Transport distance } \\
(\mathrm{km})\end{array}$ & $\begin{array}{c}\text { Transport type } \\
\text { (road/rail/ocean) }\end{array}$ & Cost $(£ K)$ \\
\hline \multirow{5}{*}{ Substructure } & Concrete & 95 & 60 & Road & 9.5 \\
\hline & Steel & 13.4 & 140 & Road & 0.4 \\
\hline & Plywood & 3.3 & 100 & Road & 5.3 \\
\hline & Block & 20.2 & 100 & Road & 3 \\
\hline & Bricks & 9.6 & 100 & Road & 3 \\
\hline \multirow{4}{*}{ Roof } & Steel & 10.1 & 140 & Road & 12.3 \\
\hline & Timber & 4 & 80 & Road & 6.6 \\
\hline & Waterborne paint & 0.6 & 70 & Road & 1 \\
\hline & Polystyrene & 0.02 & 70 & Road & 0.4 \\
\hline \multirow{7}{*}{ Walls } & Steel & 1.2 & 140 & Road & 5.5 \\
\hline & Timber & 1.3 & 80 & Road & 2 \\
\hline & Plasterboard & 2 & 90 & Road & 1.3 \\
\hline & Plaster & 0.3 & 160 & Road & 0.7 \\
\hline & Block & 62.7 & 80 & Road & 12.2 \\
\hline & Bricks & 34.5 & 100 & Road & 10.7 \\
\hline & Paint & 1.8 & 60 & Road & 2.4 \\
\hline \multirow{3}{*}{ Windows and doors } & Glass & 1 & 70 & Road & 11.9 \\
\hline & Timber & 1.2 & 80 & Road & 14.5 \\
\hline & Paint & 0.3 & 60 & Road & 0.4 \\
\hline Ceiling & Plaster & 0.4 & 160 & Road & 0.8 \\
\hline
\end{tabular}

importantly, it provides an open access to add new data or manage the existing data.

Material data can be inputted in two steps; the first step is to choose the specific materials in sequence for each subsystem of substructure, roof, walls, windows and doors, and ceiling of the plan in order to establish a material list; the second plan is to input the quantity (tons), transport distance $(\mathrm{km})$, transport type (road/rail/ocean), and cost (£k) of each material. After the inventory of each plan is completed, the carbon emission calculation and comparison will be analyzed automatically from the system. The screenshot of each option can be shown in Figure 8 .

6.2.2. Calculation and Comparison Analysis. After the material data has been inputted for the subsystem of substructure, roof, walls, windows and doors, and ceiling, the results for embodied carbon of materials and transport are obtained for each construction plan. It also provides the comparison analysis between these two plans.

The results are presented here in many forms.

(1) Specific Carbon Emission Results List. This results list shows the specific information about the plan, including material category, specific material, carbon emission factor, material quantity, transport distance and type, and the key figure, carbon emission of embodied material, transport, and the sum. This result page is shown in Figure 9.

(2) Pie Chart for the Percentage between Embodied Material and Transport. This pie chart shows the carbon emission percentage of embodied material and transport. As shown in Figure 10 for plan 1 "masonry wall," the materials and transport occupied $97 \%$ and $3 \%$ of the total $\mathrm{CO}_{2}$, respectively.

(3) Bar Chart for the Carbon Emission of Subsystem. The whole structure was divided into 5 subsystems of substructure, roof, walls, windows and doors, and ceiling. The bar chart shows the $\mathrm{CO}_{2}$ percentage and quantity of each subsystem. As shown in Figure 11 for plan 1, the substructure occupied the most part compared with the other subsystem.

(4) Bar Chart for the Carbon Emission of Different Material Types. The material types acquiesced in the system database are quarried material, timber concrete, mortars and cement, plastics, glass, miscellaneous, and so forth. The bar chart demonstrates the percentage of each material type of plan 1 as shown in Figure 12.

Based on the 4 kinds of analysis for single construction plan, the comparison analysis between plan 1 and plan 2 gathered each form in one page; in addition, other bar chats were provided to compare the quantities and percentages for each subsystem and material type (Figure 13).

6.3. Result. In the case study, the carbon emission of construction plan 1 "masonry wall" amounts to 77.8 tons, approximately $432 \mathrm{~kg} \mathrm{CO}_{2}$ per $\mathrm{m}^{2}$ of floor area (Figure 9). This carbon emission level per floor area is similar to other studies [12]. Notably, $97 \%$ of the total carbon is from the embodied materials, and only $3 \%$ were attributed to the transportation from cradle to site (Figure 10). 


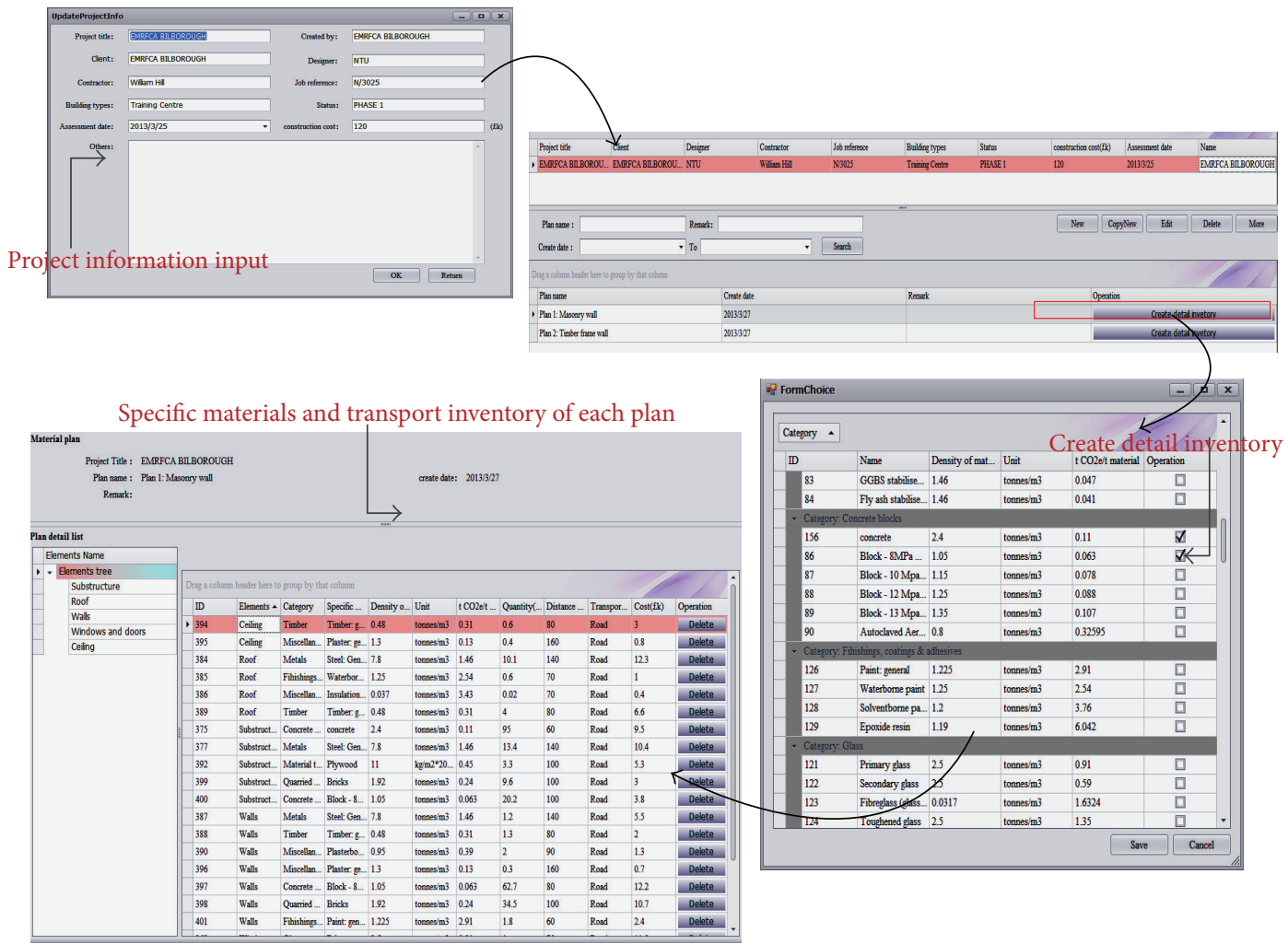

FIGURE 8: Process of basic information and inventory input.

\begin{tabular}{|c|c|c|c|c|c|c|c|c|c|c|}
\hline \multicolumn{11}{|c|}{ Plan name: Plan 1: Masonry wall } \\
\hline \multirow[b]{2}{*}{ Category } & \multirow[b]{2}{*}{ - Specific material } & \multirow[b]{2}{*}{ Density of mat.. Unit } & \multirow[b]{2}{*}{ t CO2elt material } & \multirow[b]{2}{*}{ Quantity(tonnes) } & \multirow[b]{2}{*}{ Distance betwe... } & \multirow{3}{*}{$\begin{array}{l}\text { Transport type } \\
\text { Road }\end{array}$} & \multirow[b]{2}{*}{$\operatorname{Cost}(f \mathrm{k})$} & \multicolumn{3}{|c|}{ Footprint (tonnes fossil CO2e) } \\
\hline & & & & & & & & Embodied & Transport & Sum \\
\hline OMaterial tree & $(00020007)$ Ply... & $11 \mathrm{~kg} / \mathrm{m} 2 * 20 \mathrm{~mm}$ & 0.45 & 3.3 & & & 5.3 & 1.485 & 0.0352176 & 1.5202176 \\
\hline \multirow{2}{*}{ (0001)Quarried ... } & $(0001001)$ Bric.. & 1.92 tonnes/m3 & 0.24 & 34.5 & & Road & 10.7 & 8.28 & 0.368184 & 8.648184 \\
\hline & $(0001001)$ Bric.. & 1.92 tonnes/m3 & 0.24 & 9.6 & & Road & 3 & 2.304 & 0.1024512 & 2.4064512 \\
\hline \multirow{4}{*}{ (0002)Timber } & $(00020001) \mathrm{Tim}$. & 0.48 tonnes/m3 & 0.31 & 1.2 & & Road & 14.5 & 0.372 & 0.01024512 & 0.38224512 \\
\hline & $(00020001) \mathrm{Tim}$. & 0.48 tonnes/m3 & 0.31 & 13 & & Road & 2 & 0.403 & 0.01109888 & 0.41409888 \\
\hline & $(00020001) \mathrm{Tim}$. & 0.48 tonnes/m3 & 0.31 & 4 & 80 & Road & 6.6 & 1.24 & 0.0341504 & 1.2741504 \\
\hline & $(00020001) \mathrm{Tim}$. & 0.48 tonnes/m3 & 0.31 & 0.6 & & Road & 3 & 0.186 & 0.00512256 & 0.19112256 \\
\hline \multirow{3}{*}{ (0005) Concrete... } & $(00050000)$ con... & 2.4 tonnes/ $\mathrm{m} 3$ & 0.11 & 95 & & Road & 9.5 & 10.45 & 0.608304 & 11.058304 \\
\hline & $(00050001) \mathrm{Bl}$ & 1.05 tonnes $/ \mathrm{m} 3$ & 0.063 & 62.7 & & Road & 12.2 & 3.9501 & 0.53330752 & 4.48540752 \\
\hline & $(00050001) \mathrm{Blo}$. & 1.05 tonnes/m3 & 0.063 & 20.2 & & Road & 3.8 & 1.2726 & 0.2155744 & 1.4881744 \\
\hline \multirow{3}{*}{ (0006)Metals } & $(00060005)$ Stee... & 7.8 tonnes/m3 & 1.46 & 13.4 & & Road & 10.4 & 19.564 & 0.20020672 & 19.76420672 \\
\hline & $(00060005)$ Stee. & 7.8 tonness $\mathrm{m} 3$ & 1.46 & 10.1 & & Road & 12.3 & 14.746 & 0.15090208 & 14.89690208 \\
\hline & $(00060005)$ Stee.. & 7.8 tonness $\mathrm{m} 3$ & 1.46 & 12 & & Road & 5.5 & 1.752 & 0.01792896 & 1.76992896 \\
\hline & & & & & & & Total: 117.7 & Total: 75.4893 & Total: $2.351 \ldots$ & Total: $77.84070 \ldots$ \\
\hline
\end{tabular}

FIGURE 9: Part of the specific carbon emission results list of plan 1.

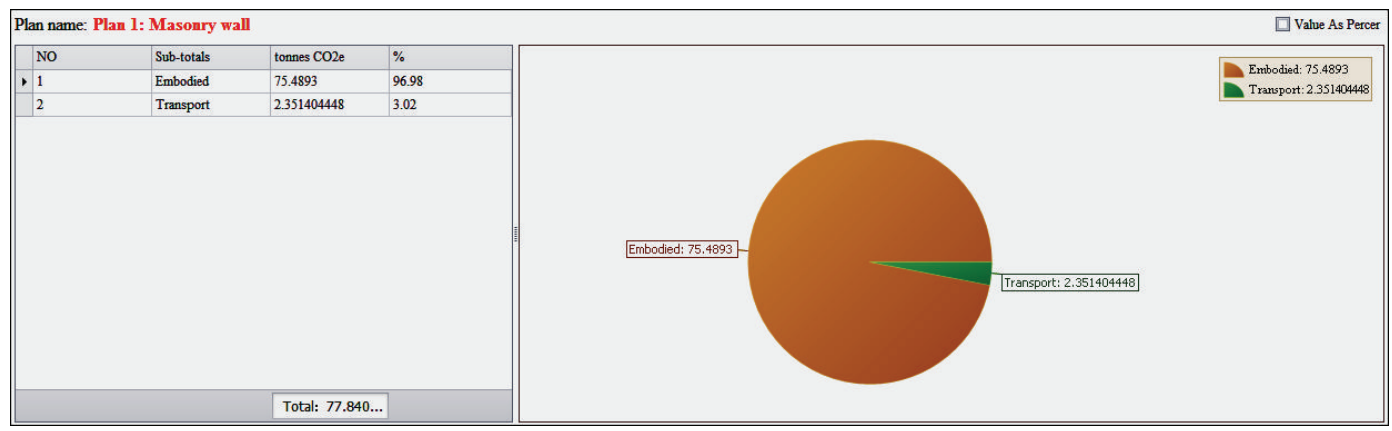

FIGURE 10: $\mathrm{CO}_{2}$ percentage between material and transport of plan 1 . 


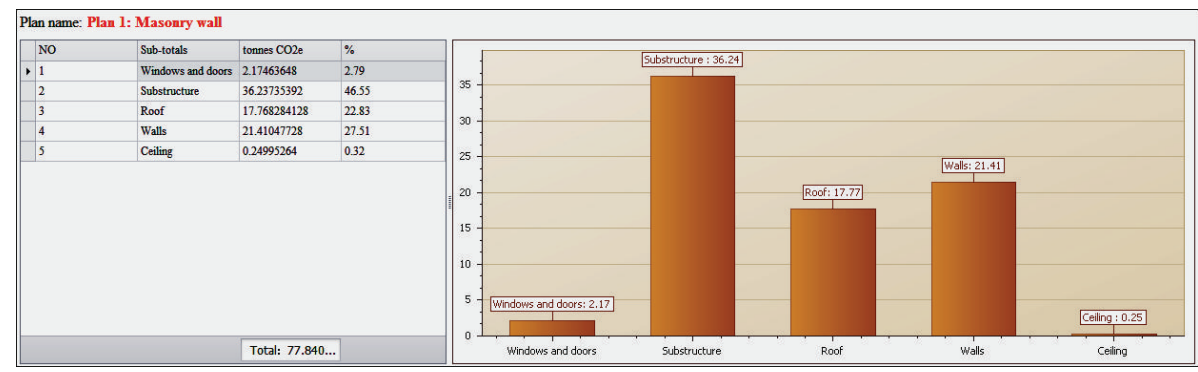

FIGURE 11: $\mathrm{CO}_{2}$ percentage of each subsystem of plan 1 .

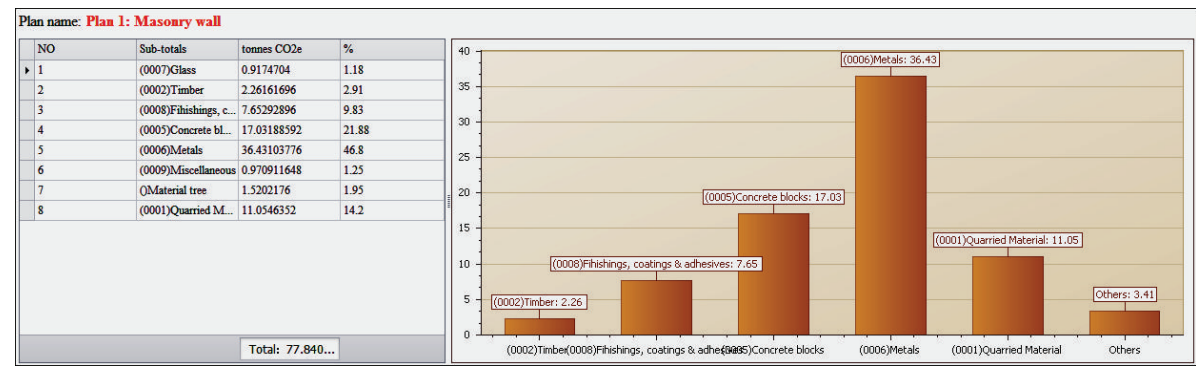

FIGURE 12: $\mathrm{CO}_{2}$ percentage of different material type of plan 1 .

The result shown in Figure 11 demonstrates that the substructure is responsible for $46.6 \%$ of the carbon emission associated with the use of steel and concrete, and $27.5 \%$ is attributed to the wall. Regarding the specific materials, metals are the most significant material type, accounting for $46.8 \%$ of the embodied material carbon. The concrete and blocks are also main contributors, accounting for $21.9 \%$, (Figure 12).

Plan 2 "timber frame wall" mainly replaced the masonry wall consisting of brick and block with timber. This plan amounts to 65.4 tons $\mathrm{CO}_{2}$, approximately $363 \mathrm{~kg} \mathrm{CO}_{2}$ per $\mathrm{m}^{2}$, reduced $16 \%$ compared with plan 1 in this case study. The quantity of carbon emission for each subsystem can be shown in Figure 14.

According to the carbon reduction between these two plans, the main contributor is the replacement by timber in the wall and decreased mass in substructure to accommodate the lighter timber wall. In addition, although the $\mathrm{CO}_{2}$ contribution by timber increased dramatically, the $\mathrm{CO}_{2}$ created by metals and concrete and blocks are relatively decreased, and the decrease is much more than the increase (Figure 15).

\section{Conclusions}

Regarding the embodied carbon performance in the case study, the result disclosed the fact that the most important contributors amongst construction materials to the total embodied $\mathrm{CO}_{2}$ were steel, concrete, and blocks used in the building, accounting for over $60 \%$ in both plans, which is also similar to the result presented by Kennedy [28]. However, an opportunity for reducing embodied energy is through use of recycling materials in the construction [29]. Steel as a high-level recycling material can bring a big reduction of carbon emission by reusing from previous deconstruction.
Therefore, builders should pay more attention not only to these quantities, but also to the recycling of the key contributors amongst the materials used in the construction, improving sustainable design as a result.

Studies [12, 30, 31] demonstrated that the embodied carbon emission of buildings varies considerably depending upon the different technology, the materials, or the process management adopted. This case study adopted plans of masonry wall and timber frame for building construction to make a comparison. The use of a timber frame produced a lighter weight compared with masonry wall, and consequently less substructure material was required. It realized the reduction of using block work, concrete, and steel reinforcement, all being key contributors for carbon emission. As expected, the timber frame wall has less embodied carbon emission than the masonry structure, realizing a $16 \%$ reduction with this study. The proper materials used in the building could not only bring the carbon reduction of the applied substructure itself, but also provide other additional benefits such as reduced earthworks requiring, less spoil, and waste material for export off site. Using the system is a clue for designers or contractors in how to choose more sustainable materials and arrange the construction processes arising.

Based on the partial LCA framework conducted in construction phase and the background of LCA tools, a carbon calculation system was designed to support the calculation of the carbon emission of the construction plan by the participants for sustainable optimization. Comparing with current LCA tools introduced above, the unique functions of this system can be concluded as follows.

(1) This system focuses on the carbon emission assessment in building construction. An integrated database including the carbon emission factors of 


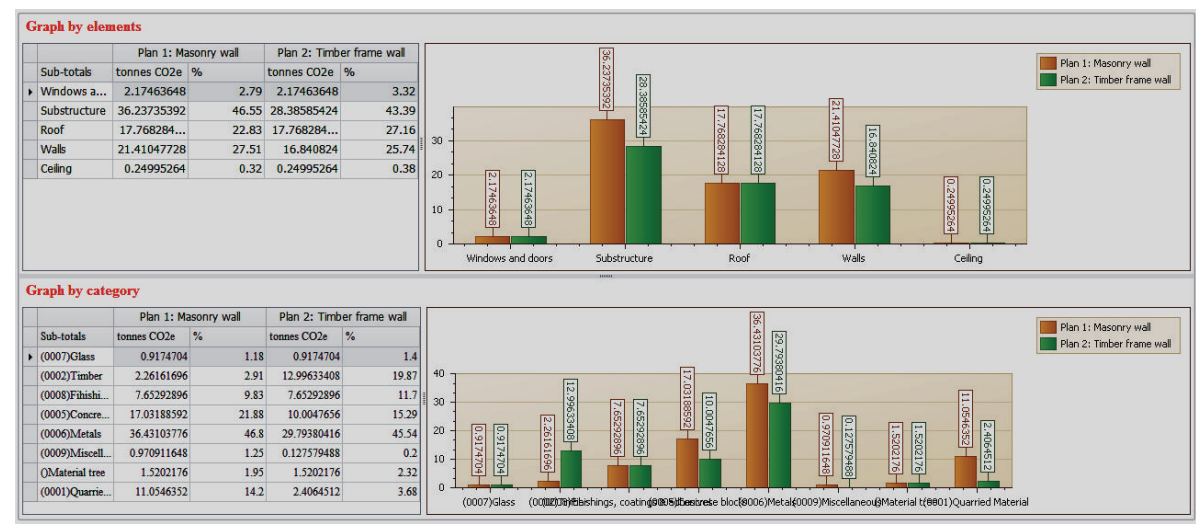

FIGURE 13: Comparison analysis between plan 1 and plan 2.

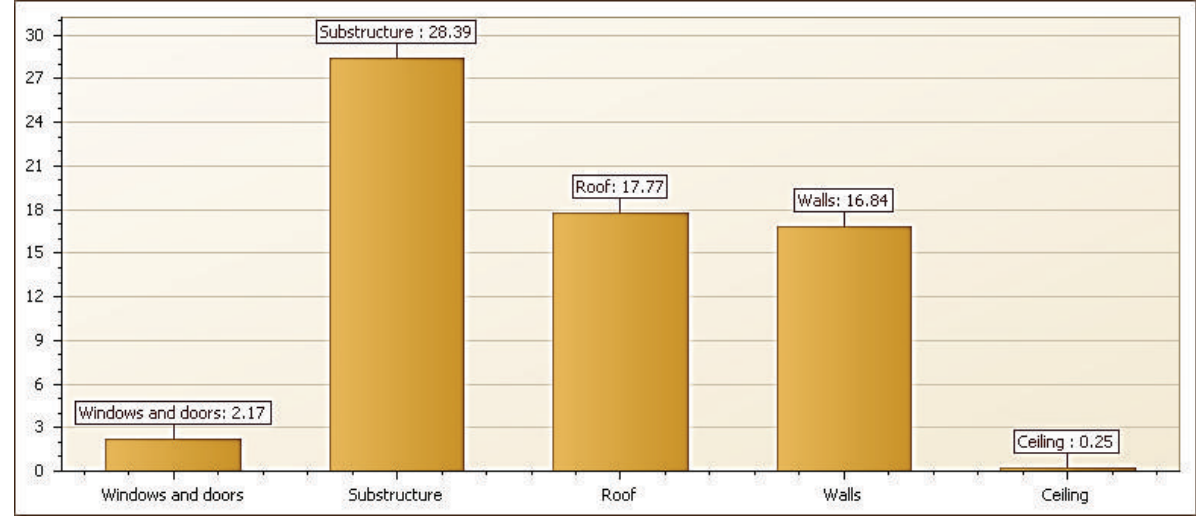

Figure 14: $\mathrm{CO}_{2}$ quantity of each subsystem in plan 2.

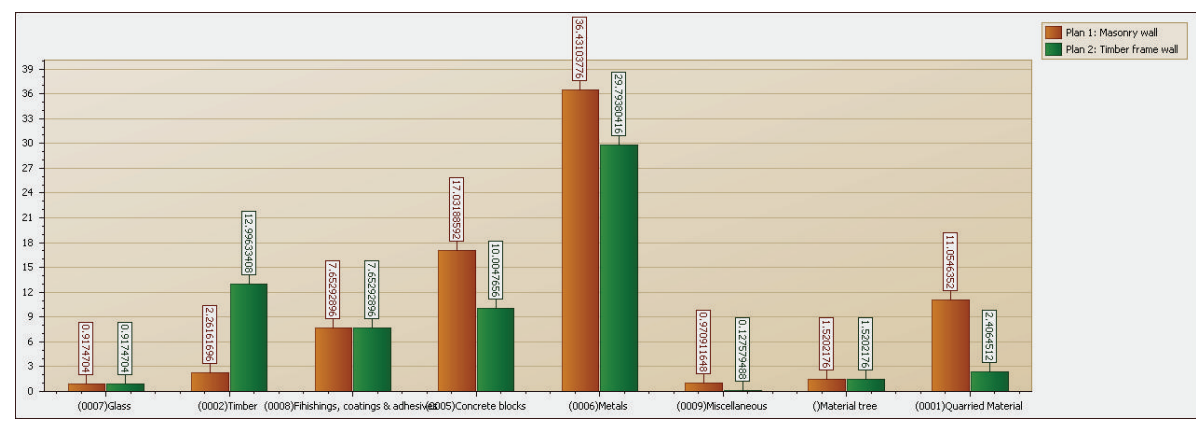

FIGURE 15: $\mathrm{CO}_{2}$ comparison analysis between plan 1 and plan 2 by materials.

building materials, transport, and equipment is used within this system. The three databases hardly appear in a LCA tool at the same time, especially the database of construction equipment.

(2) This system provides an open access for users to edit or revise the data for special performance or add new factors into the database for using new technology or materials introduced to the market. In addition, users can define the different substructures of a building according to their specific demand and then make a comparison amongst these substructures.
(3) 4 output forms are provided in this system to demonstrate the results for single plans and additional comparison actions between different plans. The various performance forms make the operation and results much simpler and clearer compared with other tools.

This system provides a more practical application in building construction, and it is essential for designers to be able to quantify the sustainable benefits of design for building construction project in the design stage, and the system provides decision support for sustainable building design and construction. 


\section{Conflict of Interests}

The authors declare that there is no conflict of interests regarding the publication of this paper.

\section{Acknowledgment}

Many thanks are given to Andrew Hill of William Hill Building Contractors Ltd for providing the project data for this study.

\section{References}

[1] V. M. Taborianski and R. T. A. Prado, "Methodology of $\mathrm{CO}_{2}$ emission evaluation in the life cycle of office building façades," Environmental Impact Assessment Review, vol. 33, no. 1, pp. 4147, 2012.

[2] IPCC, Climate Change 2007-The Forth Assessment Report of the Intergovernmental Panel on Climate Change, IPCC, Geneva, Switzerland, 2007.

[3] P. Jiang and N. K. Tovey, "Opportunities for low carbon sustainability in large commercial buildings in China," Energy Policy, vol. 37, no. 11, pp. 4949-4958, 2009.

[4] T. Malmqvist, M. Glaumann, S. Scarpellini et al., "Life cycle assessment in buildings: the ENSLIC simplified method and guidelines," Energy, vol. 36, no. 4, pp. 1900-1907, 2011.

[5] European Commission. Joint Research Centre. Institute for Environment and Sustainability, International Reference Life Cycle Data System (ILCD) Handbook. General Guide for Life Cycle Assessment. Detailed Guidance, EUR, 24708 EN, Publications Office of the European Union, Luxembourg, 1st edition, 2010.

[6] ISO 14040, Environmental Management: Life Cycle Assessment Principles and Framework, Internation Standards Organisation, Paris, France, 2006.

[7] I. Sartori and A. G. Hestnes, "Energy use in the life cycle of conventional and low-energy buildings: a review article," Energy and Buildings, vol. 39, no. 3, pp. 249-257, 2007.

[8] D. D. Tingley and B. Davison, "Developing an LCA methodology to account for the environmental benefits of design for deconstruction," Building and Environment, vol. 57, pp. 387-395, 2012.

[9] European Commission, "Critical review of current research needs and limitations related to ISO-LCA practice," 2008, http://www.leidenuniv.nl/cml/ssp/publications/calcas_report_ d7_annex_1.pdf.

[10] T. Ramesh, R. Prakash, and K. K. Shukla, "Life cycle energy analysis of buildings: an overview," Energy and Buildings, vol. 42, no. 10, pp. 1592-1600, 2010.

[11] G. P. Gerilla, K. Teknomo, and K. Hokao, "An environmental assessment of wood and steel reinforced concrete housing construction," Building and Environment, vol. 42, no. 7, pp. 2778-2784, 2007.

[12] J. Monahan and J. C. Powell, "An embodied carbon and energy analysis of modern methods of construction in housing: a case study using a lifecycle assessment framework," Energy and Buildings, vol. 43, no. 1, pp. 179-188, 2011.

[13] H. Yan, Q. Shen, L. C. H. Fan, Y. Wang, and L. Zhang, "Greenhouse gas emissions in building construction: a case study of One Peking in Hong Kong," Building and Environment, vol. 45, no. 4, pp. 949-955, 2010.
[14] G. Bin and P. Parker, "Measuring buildings for sustainability: comparing the initial and retrofit ecological footprint of a century home-the REEP House," Applied Energy, vol. 93, pp. 24-32, 2012.

[15] J. S. Cooper and J. Fava, "Life-cycle assessment practitioner survey: summary of results," Journal of Industrial Ecology, vol. 10, no. 4 , pp. 12-14, 2006.

[16] The National Institute of Standards and Technology (NIST), "BEES online tutorial," http://ws680.nist.gov/Bees/ (A(4adlR5muzwEkAAAANjZiOGVhMzYtMTIxYy00ODc2L WFiNzAtOGVjMmVhNjllZjBlQ8t6eKvtnd2F6NQBd_ YiqT1c9RM1))/Help.aspx.

[17] Athena Sustainable Materials Institute, "Athena Impact Estimator for Buildings V 4.2 Software and Database Overview," 2012, http:// calculatelca.com/wp-content/uploads/2011/11/ImpactEstimatorSoftwareAndDatabaseOverview.pdf.

[18] Japan Sustainable Building Consortium (JSBC), "CASBEE for new construction: technical manual," 2010, http://www.ibec.or .jp/CASBEE/english/download/CASBEE-NC_2010manual.pdf.

[19] Environment Agency, "Waste and resources assessment tool for the environment (WRATE)," 2012, http://www.environmentagency.gov.uk/research/commercial/102922.aspx.

[20] G. A. Blengini, "Life cycle of buildings, demolition and recycling potential: a case study in Turin, Italy," Building and Environment, vol. 44, no. 2, pp. 319-330, 2009.

[21] S. Tae, C. Baek, and S. Shin, "Life cycle $\mathrm{CO}_{2}$ evaluation on reinforced concrete structures with high-strength concrete," Environmental Impact Assessment Review, vol. 31, no. 3, pp. 253260, 2011.

[22] S. Tae, S. Shin, J. Woo, and S. Roh, "The development of apartment house life cycle $\mathrm{CO}_{2}$ simple assessment system using standard apartment houses of South Korea," Renewable and Sustainable Energy Reviews, vol. 15, no. 3, pp. 1454-1467, 2011.

[23] D. Yu, H. Tan, and Y. Ruan, "A future bamboo-structure residential building prototype in China: life cycle assessment of energy use and carbon emissi," Energy and Buildings, vol. 43, no. 10, pp. 2638-2646, 2011.

[24] M. Suzuki and T. Oka, "Estimation of life cycle energy consumption and $\mathrm{CO}_{2}$ emission of office buildings in Japan," Energy and Buildings, vol. 28, no. 1, pp. 33-41, 1998.

[25] A. Sharma, A. Saxena, M. Sethi, and V. Shree, "Life cycle assessment of buildings: a review," Renewable and Sustainable Energy Reviews, vol. 15, no. 1, pp. 871-875, 2011.

[26] Price water house Coopers (PwC), "TEAM, Ecobilan's life cycle assessment tool," 2013, http://ecobilan.pwc.fr/en/boite-aoutils/team.jhtml.

[27] University of Bath, "Inventory of carbon \& energy(ICE), version 1.6a," 2008, http://perigordvacance.typepad.com/files/ inventoryofcarbonandenergy.pdf.

[28] C. A. Kennedy, "A comparison of the sustainability of public and private transportation systems: study of the Greater Toronto Area," Transportation, vol. 29, no. 4, pp. 459-493, 2002.

[29] A. Shukla, G. N. Tiwari, and M. S. Sodha, "Embodied energy analysis of adobe house," Renewable Energy, vol. 34, no. 3, pp. 755-761, 2009.

[30] B. V. V. Reddy and K. S. Jagadish, "Embodied energy of common and alternative building materials and technologies," Energy and Buildings, vol. 35, no. 2, pp. 129-137, 2003.

[31] A. H. Buchanan and B. G. Honey, "Energy and carbon dioxide implications of building construction," Energy and Buildings, vol. 20, no. 3, pp. 205-217, 1994. 


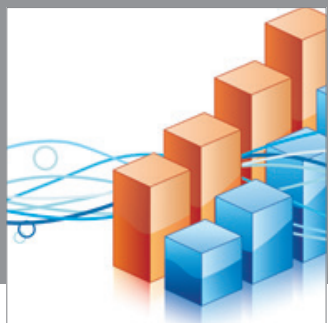

Advances in

Operations Research

mansans

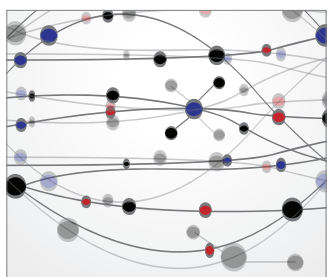

The Scientific World Journal
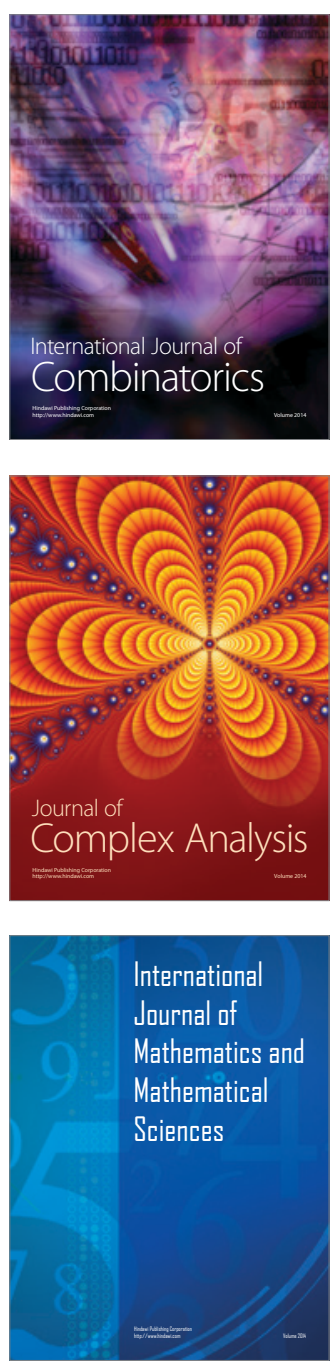
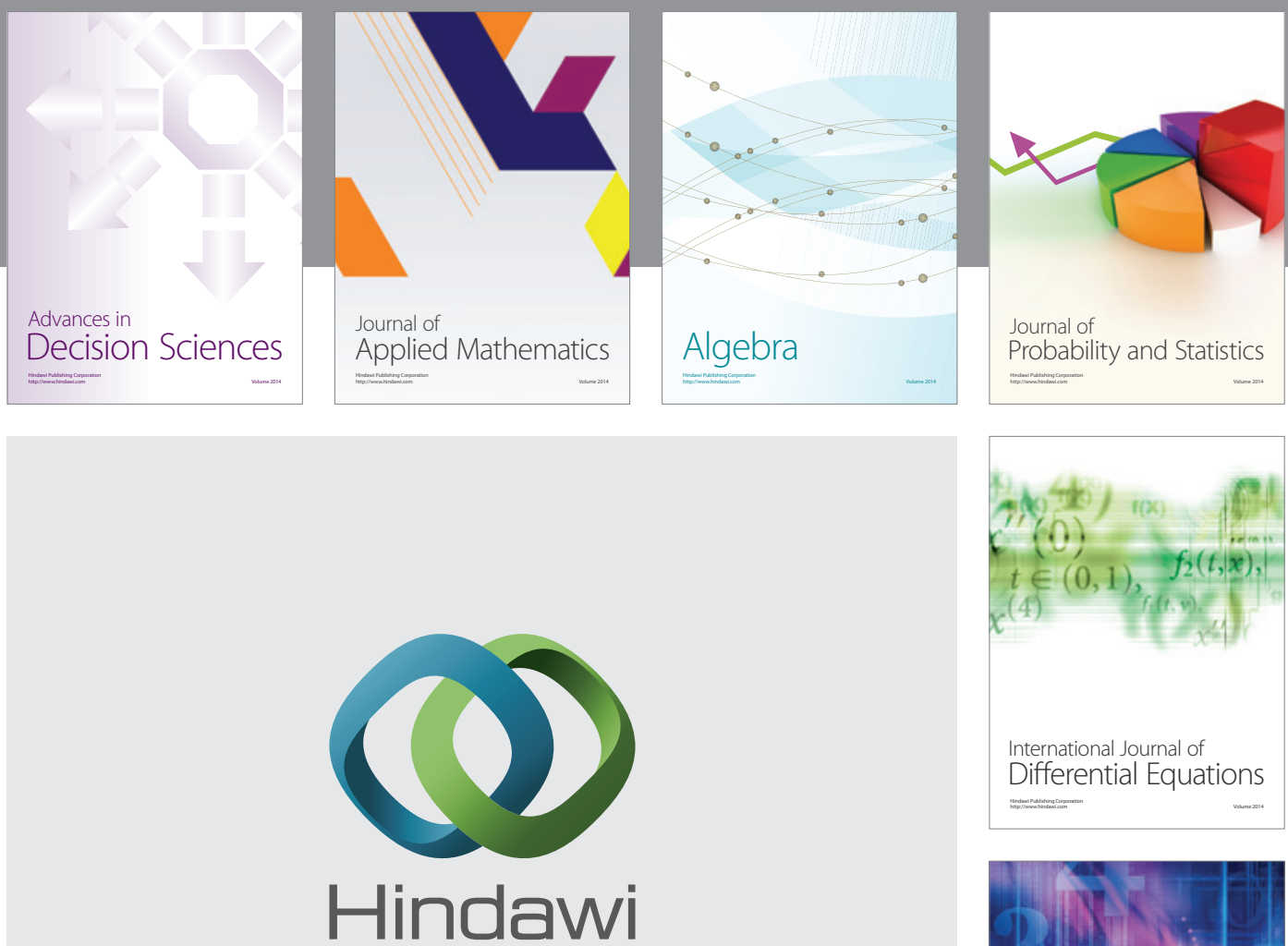

Submit your manuscripts at http://www.hindawi.com
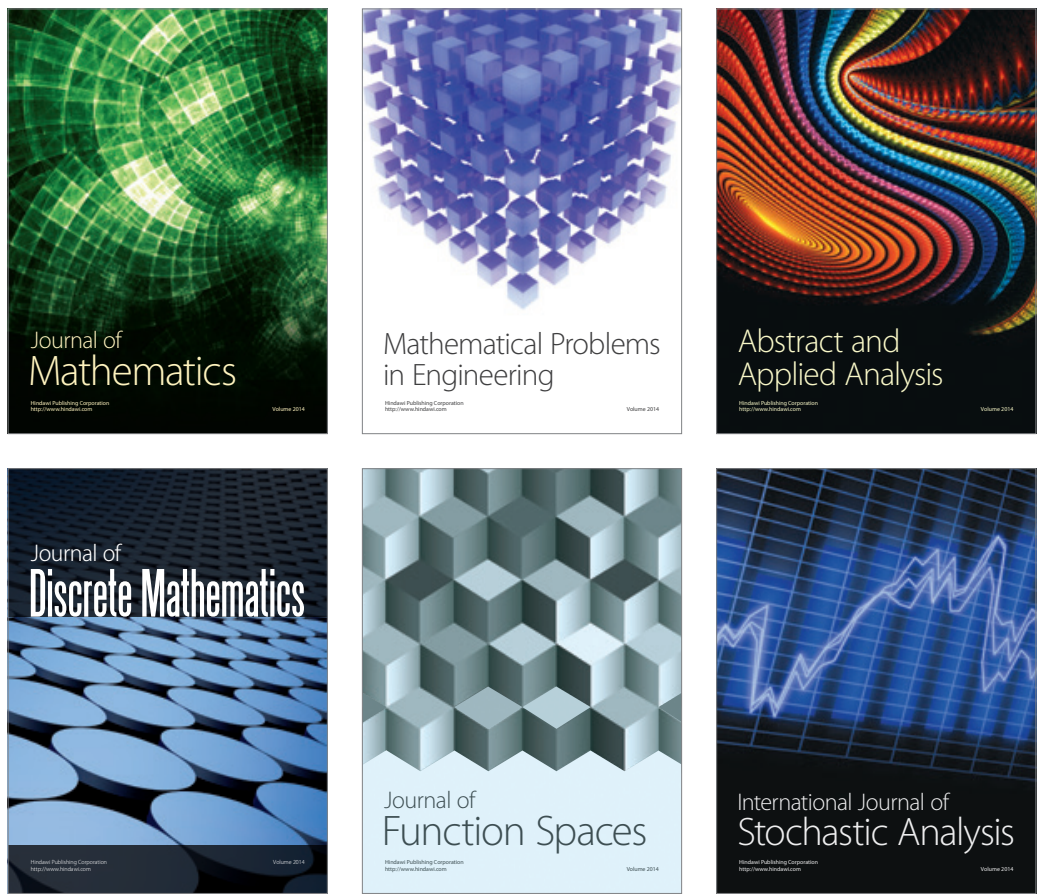

Journal of

Function Spaces

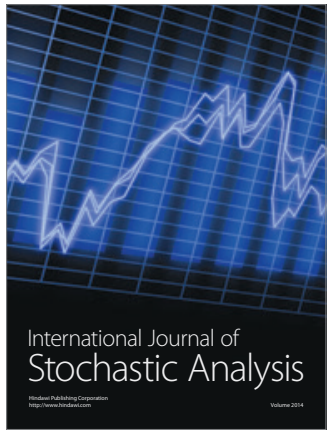

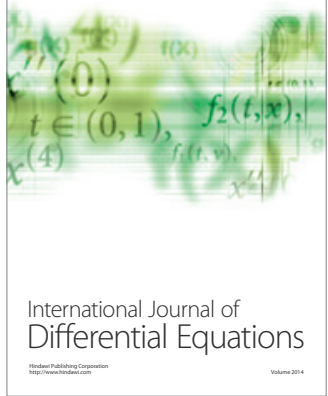
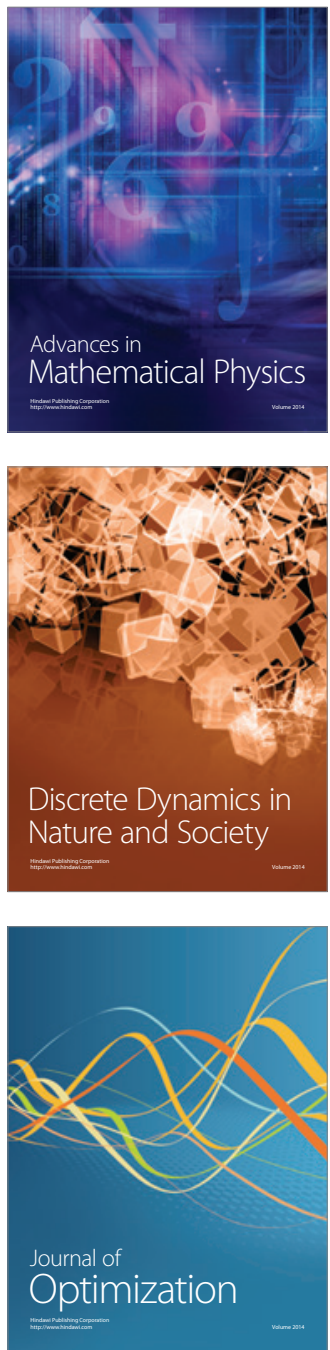